\title{
Teachers' Motivation Related to Teaching and Learning Processes
}

\section{Bettina Steren dos Santos, Denise Dalpiaz Antunes², Juan José Mouriño Mosquera ${ }^{3}$, Claus Dieter Stobäus ${ }^{4}$}

\author{
${ }^{1}$ Postgraduate Program in Education, Pontifical Catholic University of Rio Grande do Sul, Porto Alegre, Brazil \\ ${ }^{2}$ Graduate Program of Education, Universidade Federal de Pelotas-UFPel, Pelotas, Brasil \\ ${ }^{3}$ Postgraduate Program in Education, Pro-Rectory of Postgraduate and Research, Pontifical Catholic University of Rio Grande do Sul, \\ Porto Alegre, Brazil \\ ${ }^{4}$ Postgraduate Program in Education and in Biomedical Gerontology, Pontifical Catholic University of Rio Grande do Sul, Porto \\ Alegre, Brazil \\ Email: stobaus@pucrs.br
}

How to cite this paper: dos Santos, B. S., Antunes, D. D., Mosquera, J. J. M., \& Stobäus, C. D. (2016). Teachers' Motivation Related to Teaching and Learning Processes. Creative Education, 7, 2011-2020. http://dx.doi.org/10.4236/ce.2016.715202

Received: June 30, 2016

Accepted: September 3, 2016

Published: September 6, 2016

Copyright $\odot 2016$ by authors and Scientific Research Publishing Inc. This work is licensed under the Creative Commons Attribution International License (CC BY 4.0).

http://creativecommons.org/licenses/by/4.0/

\begin{abstract}
We use theoretical fields about aspects of the Teaching and Learning processes related to the Motivational Process and reviews elements of the conceptualization of motivation, as a process who involves external/extrinsic and internal/intrinsic components, including elements of interpersonal relationships. The research data are qualitative, using 34 teachers' field diaries, obtained after the workshops developed with them, complemented with our infield (unsystematic) observations, in three schools, about: their pedagogical practice, motivation, aspects of his/her malaise and well-being, reflections about their self-image and self-esteem, autonomy and cooperation for motivation in education. Their qualitative speeches were pointed on field diaries, complemented with observations, obtained in the meetings with these teachers. They are analyzed by Content Analysis Technique and the categories we found are: 1) Initial conceptions that subjects bring on the subject motivation; 2) Relation between malaise/wellbeing and teacher's motivation; 3) Relation among self-image, self-esteem and motivation; 4) Cooperation for motivation in the profession. We stress the need and importance of conducting positive aspects related to the subjectivity aspects of the teacher and students' relationships, remembering that the three components (knowledge, skills and attitudes/affect) interact constantly. We still see that our field research needs to be expanded, with a view to provide continuing education for the teachers (also students and parents) to make them aware of the importance of motivation related to his/her well-being.
\end{abstract}

\section{Keywords}

Motivation, Teaching/Learning Processes, Interpersonal Relations, Self-Esteem 


\section{Introduction}

By analyzing the actual educational reality, we can observe that the situation in the schools, especially in the classrooms often reveals a lack of motivation, both for students and teachers. In dialogic relationship between learning and education, we note that a low level of motivation, lack of enthusiasm, lack of curiosity or loss of stimulus pose a risk for students' school failure. Realizing these obvious transformations and transporting them into the institution is essential to point out that teachers' teaching must be designed comprehensively and encouragingly, and the students must be encouraged in more provocative and positive environments, with their peers, parents, neighbors, and the society.

As good or better teachers we must pass a road a little beyond simple awareness teaching, in order to overcome patterns for effective educational practice, with more and good motivation. So we can compose with more clarity references of each educator and knowledge stemming from their experiences as well as understand and embrace the knowledge that each student has already and is able to continue to develop themselves, attempting unique individual development as an individual, a different person, with differences as requirements, moments and personal rhythms.

Our text was constructed from the presentations and discussion of our ideas at the group.

The major research questions that guide us are: How is the motivation before and after implementing the workshops of self-knowledge? How is the teacher malaise before and after implementing the workshops of self-knowledge? How are self-image and selfesteem before and after implementing the workshops of self-knowledge? How do the workshops of self-knowledge affect the research subjects?

The research was approved on Ethical Committee at PUCRS-Pontifical Catholic University of Rio Grande do Sul-PUCRS.

\section{Theoretical Field}

We use Theoretical Field based on the human development theories, focusing on teaching and learning, specifically on cognitive theories of motivation, in the following directions: motivational processes and their complexity, tangible concepts to teaching and learning and reflections on interpersonal relationships in everyday life. Remembering the lifespan approach, it gives the idea that we are never completely developed and ready so that a person is always learning, so can be teaches during his/her entire life.

So, learning can be achieved during many moments with no explicit organization (alone, at home, on trips, at socialization processes, in a theater). Also on more formal moments, as at organizations like in schools or universities, like on courses or workshops with includes organized Teaching and Learning Processes.

The idea is to contextualize the studies on motivation, teaching and learning and to expose what theoretician is opted to use in this field for the analysis.

In these moments there can be moments of interactions and reflections, enhancing know ledges, abilities and attitudes/affect, who lead to the capability to learn to learn, as 
a constant process between persons, in these case a teacher and a student, the most of the time at an educational setting.

Another point that can be enhanced is the constant Interpersonal Relationships, in the case of the formal school can be (well) planned in an educational organized intervention, who gives a possibility to establish positive interactions, resulting in possible elements who can be evaluated.

\section{Motivation as a Process}

As we know, human motivation is linked to human behavior, and is one of the factors in investigations in education, to better understand the educational context.

Huertas (2001) warns that it is difficult to conceptualize motivation. Based on his studies, he says that motivation is understood as a continuous process, which precedes human action. Sometimes is inherent in the human body (in the prefrontal region of the brain, corresponding to interest the task with an end in itself and not as a means to achieve a goal), sometimes extrinsic (when attention to the task is related to the achievement of the goal, the task seen as a means).

Motivation can also be defined as a motivational process. Extrinsic motivation objective a result, the stock price is subject to this result. If so, there are more chances of repeating the "good" task and therefore tolerance to perform the actions is linked to the likelihood of successful outcome, when approved in the social context one lives. In intrinsic motivation, as self-motivation, the goal is the action itself and the result is seen as a natural secondary, must the time proving "myself that I can do it well". Success is always expected, but in case of failure, the attempt would have been valid as personal experience, as interaction with people and environment.

Intrinsic motivation corresponds to a typically self-determined behavior, in which the interest in an activity is guided by free choice, by spontaneity and curiosity. The efforts dedicated to the realization of an activity are not linked to external contingencies and rewards, but with the inherent characteristics to activity (Deci \& Ryan, 2000). In this term, in which tasks have ends themselves, theorists report that intrinsically motivated behavior is more associated with feelings of satisfaction, fulfillment and pleasure (Deci \& Ryan, 1985; Deci \& Ryan, 2000).

In the extrinsic motivation, activity or task is subject to the achievement of a goal or outcome. According to authors such as Deci \& Ryan (1985) and Deci \& Ryan (2000), in this situation the realization of actions is closely related to rewards, reviews, terms, punishments, praise, among others. What determines the behavior is much more associated with the control, touted by external wills in which the individual acts under pressure, to the detriment of free will and autonomy. In this controlled behavior, the subject tends to perceive the activities/tasks as instrumental for achieving certain goal. However, that figure in the foreground is the ultimate goal and not the very task activity.

As in a system of relations, interrelations and actions, motivation in each person will be composed of internalized factors during development and external circumstances. 
i.e., external actions, after interpreted in a socio-cultural context and daily life of each individual, become significant and important also as intrinsic motivation (Antunes, 2016: p. 60).

In this sense, the motivational process is shaped by actions with intrinsic and extrinsic reasons. Perhaps the latter directly represent the development of the first actions, internalized through the meanings of social motivation in each relationship. For motivation is personal process, not always conscious development. There are factors that can be internalized as intrinsic. External factors, for the subject, constitute sociocultural reasons that differentiate in various social contexts (Antunes, 2016: p. 54).

However, the motivational process has relations with the origin of the reasons that precede a goal and the consciousness we have of them. In every situation in which an individual think and then act, it is an implicit target, which can refer to many different individual intentions, for example, the improvement in Education, the achievement of something as desire, among others. The goals in this sense can be characterized as affective, cognitive, personal relationships, organizational subjectivity, or even related to the actual task to which one are intended.

\section{Teaching and Learning Are Processes}

Teaching and to learning are processes related to the human development, when we speak about intentional educational process. There are some important moments with in teaching who promote (controlled) extrinsic motivation, not as behavior control bust as promotion of "controlled" situation at an educational environment who gives the student the opportunity to learn something.

If he/her is also intrinsically motivated, it is possible that occurs some kind of cognitive, affective and social improvement in direction of (re)make of previous acquisitions, evolving from a stage of knowledge, skills and attitudes to a new stage, as says Vygostky (1989), in the "proximal/potential development zone" one haves. These is the idea who makes the difference on education, the presence of a tutor, a mediator of knowledge, skills and attitudes, in the direction of do better performances as before.

In a broader context, as social environment, there are also occasions one needs to give extrinsic motivation, as a caregiver, a not formal educator, as a family member or friend, in a not so controlled context as formal education. Ore as informal education moments too, giving for example any information to someone at phone or at press.

Then, as a motivational mediator in an educational process, in the different levels as educator, the teachers must know how researchers speak about motivation.

Teachers and students (both subjects of their own teaching and learning) go through constant processes of cognitive, socio-affective and skill development, where there is interchange with the medium in which they are inserted and acting. So, preparing this medium for better educational processes is essential.

As we said (Mosquera, Stobäus, \& Santos, 2013), these processes should be seen as a production shared between the two (teacher and student) and along with the content in contextualized situations. In an educational interaction, both play distinct roles but 
equally are essential and fully interconnected, considering that teachers help his/her students in the process and vice versa, when students also helps his/her teachers.

In different educational settings, with various characteristics and intervening variables, both students and teachers are subjects in relationship, different levels knowledge, skills, affectivity and also motivation, and that may constitute much "problems" if both, more one as teacher, does not have a clearly concepts these themes, when not understand well how these processes of teaching and learning happens together (Vygotsky, 1989; Piaget, 1987; Coll, Marchesi, \& Palacios, 2004).

The most common theories listed by de Jesus (2004) and dos Santos, Stobäus, Antunes, Bernardi, \& Villas-Boas (2008a) about motivation are the following.

- Nuttin's Relational Theory-Presented by Nuttin in 1967-is a temporal perspective of a subject on motivational objects from the past, present, future, in a given situation. The temporal attitude refers to the positive or negative character, pleasant or unpleasant of motivational objects, past, present, future. So that investigation demonstrate that students with a more positive attitude toward the future, combined with a greater awareness of the study as instrumental to achieve future goals, have a higher motivation to study and better school results, regardless of their intellectual level.

- Deci's Intrinsic and Extrinsic Motivation: the author says, in 1975, that those students who have higher intrinsic motivation to perform certain tasks are the ones that get better results in these tasks. Also found that introducing external rewards, after performing successful tasks that students like to perform, decreases the interest in carrying out these tasks when the reward is withdrawn. According to the theory of intrinsic motivation, this decrease is because the reward decreases the space of autonomy. It concluded that, in general, students with internal control expectations get better school results, compared to those with external control.

- Bandura's Theory of Self-Efficacy-Expectations, put the author in 1977, of personal efficacy is the belief that the subject has that can successfully perform the behavior required to produce the desired results. There are four sources of information for this theory: behavioral achievement, vicarious experience, verbal persuasion and emotional activation.

- Rotter's Social Learning Theory-control result expectation that investigations, in 1990, pointed out that, increasingly, the subjects have external control expectations of results. For the student to develop a greater expectation of internal control of their school performance, learning study methods should be promoted and should be clarified certain inadequate beliefs that may underlie the external control expectations, such as Professor not like me, and soon I will be able to get a good score. When one belief that the results are derived from "luck", fate or other more powerful, it is considered that the subject has expectations of external control. When he/her believe that the results are contingent on their own behavior or their relatively permanent characteristics are considered to have expectations internal control.

- Weiner's Causal Attribution Theory-This theory, from 1992, explores the explanations that have subject to the results, successes or failures, according to several dimensions. The more internal, stable and global assignments are for the failures ob- 
tained, the greater the expectation of failure and therefore greater discouragement.

We put out that (dos Santos, Stobäus, Antunes, Bernardi, \& Villas-Boas, 2008b: p. 7):

From these references, it is clear that it is necessary to think of motivation as a constructive process of being human, developed at each stage of your life. The teacher, who is in adulthood, should undertake their initial and continuing education, self-training, always in search of self-concept and more positive self-realization, to enable this walk and development potential, meeting individual needs and life purposes, to self-knowledge.

One can also believe in the participation of intrapersonal and interpersonal movements, as part of my multiple intelligences. For example, as a shy person I can perform some skills that I believe that can better motivate myself or another person in some known environment, but not in another unknown. Also in terms of interrelationships, interpersonal relations, in different contexts I can be the same person but demonstrate different levels of motivation.

In other words (dos Santos, Stobäus, Antunes, Bernardi, \& Villas-Boas, 2008a), the school and it's routine are constituted within the framework of social, affective and cognitive sets, turning into a favorable (or not so) environment for the establishment of "good" interactions between people, and through them, supported in an educational plan- ned/controlled intervention, in order to trigger learning fundamental processes to perform learning processes.

Another point to argue is the possibility to interconnect these ideas with the Positive Psychology, as said by Argimon, Esteves, Cerutti, Mosquera, \& Stobäus (2015), when the teacher comes older, or as a elderly person, who have much knowledge, abilities and positive attitudes, is some kind of expertise, who can motivate the new generations with his/her personal and professional examples.

\section{DATA Analysis}

Our research can be described as a case study (Stake, 1998) and a qualitative study about the speaks from 26 teachers of three schools of Porto Alegre-BR, about their pedagogical practice, their motivation, aspects of teacher's malaise and wellbeing, reflections on their self- image and self-esteem, autonomy and cooperation for motivation, in education context.

Teachers participated in the educational workshops are of three schools of Porto Alegre-RS (two public schools, one state and the other municipal, and the third one is a school private). As the workshops occurred at different times, the participants' average was thirty-four (one time more, one time less teachers). In the municipal school participated ten teachers, in the state school sixteen and in particular eight teachers attended as self-knowledge workshops, so there were 34. It notes that the number of participants in each workshop was not constant, considering that they were conducted in a period long course. They are between 26 and 60 years old and were from Pedagogy and others degrees (Sciences, History, Geography, Mathematics...).

The qualitative data of notes of qualitative recorded teachers in field diaries, obtained 
after the workshops with the teachers, complemented with our infield (unsystematic) observations.

The data were analyzed by Content Analysis Technique, according to Bardin (2013). The most related references used were Huertas (2001), with his sociocultural contributions, and Deci \& Ryan (1985, 2000), with their self-determination theory.

The categories we found were: 1) Initial conceptions that subjects bring on the subject motivation; 2) Relation between malaise/well being and teacher's motivation; 3 ) Relation between self-image, self-esteem and motivation; 4) Cooperation for motivation in the profession.

1) Initial conceptions that subjects bring on the subject motivation: teachers confirmed certainties, by claiming that motivation is essential for human life, it is internal and is related to life goals. Thus we can see that these ideas are associated with initial concepts presented by the authors who study motivation, and doubts, which expressed almost in full, the interest in knowing how to motivate their students, or looking for a method to develop the motivation of their students. With these ideas, it appointed to the need for individual and group experiences, consisting of different educational moments, helping to compose new concepts about personal motivation, reflecting on his student development needs and possibilities.

2) Relation between malaise/well being and teacher's motivation, in which the three institutions one can see that teachers have a high index of malaise professional aspects already, studied by Esteve (2004) and de Jesus (2007). We found that this led teachers to search for simplistic solutions and effective to be applied in the classroom.

In addressing the topic malaise in teaching, we can't forget the links between historical moments, political and personal experiences, as says Esteve (2004), they may provide further explanation of dynamics and levels of final causes of this malaise. We believe that all teachers are more aware of the need to better understand their social reality and their own personal development, to go better in a well being direction. The development themes on self-awareness workshops facilitated reflections on these aspects of malaise, when they experience group activities, new ways of perceiving themselves, promoting aspects in the development of well-being and health motivation. Modernly we believe on the aspects of Heath Psychology and Positive Psychology (Mosquera; \& Stobäus, 2016), and the construction of the identity (Rodrigues, Stobäus, \& Mosquera, 2016).

3) Relation between self-image, self-esteem and motivation, which are the result of both interpersonal relationships and intrapersonal established throughout its existence. People who interact in different environments: family, school and society. Thus, the affective dimension is not genetically determined, because the person is not born with a self-image and self-esteem formed, only with interactions they are formed in the environment they live in, says Vygotsky (1989). We note, in the workshops offered, that teachers have initially difficulty to stop and reflect and expose him/herself. The interactions provided self-knowledge and new insight from their peers, and interpersonal relationships become more positive. Thus, we believe that positive interpersonal relationships in the workplace, favor the construction of positive self-image and self-esteem, 
since it is one of the social indicators of real self-concept, a summary table that makes you the "person you want to be and you are" (i.e. the view that has about yourself). The self-image is characterized in a dynamic photography that comes from telling us, then it follows from self-recognition, connected directly, and self-image develops from as we say, after our learning in contact with the examples, suffering severe inter-influence with/in the experiences in the context who one lives, stressed by Mosquera (1984) and Mosquera \& Stobäus (1984).

4) Cooperation for motivation in the profession, detached from the workshops of self-knowledge, in which cooperative work in which some teachers had difficulties in accomplishing a cooperative work, manifesting incompatibilities to work together with colleagues, without reaching a consensus for complete the task and proposed designs. However other participants demonstrated they can ease deal with colleagues and consequently became involved with the activity, being positively motivated.

In another study (dos Santos, Stobäus, \& Mosquera, 2007) we observed that the Information and Communication Technologies, when well known and the teachers at the school were prepared in their use and applications, gives them the safety and support in implementing more and new uses in the classes and in works that include homework, investigation on the Internet.

We can also say in these days that there are a new possibility of their use in education, the "gamification" of tasks, with the use of the games in the school as another "learning object", which can be used by the learners anytime and everywhere, many times, so they can lean on personal conditions and rhythms.

And in the studies from dos Santos, Stobäus, Antunes, Bernardi, \& Villas-Boas (2008a) and dos Santos, Stobäus, Mosquera, Antunes, \& Bernardi (2008b), utilizing workshops on self-knowledge and improving teacher's motivation, there was one improvement on self-image, self-esteem levels, which were more realist/positive.

The interrelations also were better accepted and there were more relationships in the direction of the goals proposed in the workshops, with the possibility of the improvement also in their school.

As we said (Stobäus, \& Mosquera, 2014: p. 536), there are three pillars on the Positive Psychology, based on major elements as follows: Positive Emotions, Positive Traits and Positive Institutions.

"Positive Emotions, which can be the joy, hope, devotion and gratitude, seeming to have been forgotten for many years, and the positive emotions still try to look better are, by nature, one of the strongest pillars of Positive Psychology.

Positive Traits, an important step towards achieving a fulfilling life or as recognized Seligman, a bigger and better well-being, must have knowledge and cultivate those inner variables or personality traits that help us be better and happier pillar.

Positive Institutions, as in these societies who aspire to own a set that supports, encourages and enhances positive emotions, positive feelings and personal strengths should thrive on Positive Institutions, as are democracies, well-structured family, the freedom of information and communication, economic and social security and especially, good Education". 
We commented also that all this are, in addition to its vital to academic work and social importance, great promoters of the development of identity and, very strongly, the building itself, especially in enablers and provocative environment. We are convinced that, as educators and caregivers, we must be extremely linked to human well-being, especially when picked in healthy institutional levels of motivation, growth and selfrealization.

\section{Conclusion}

At these moments, we want to emphasize that the relations between motivation and teaching and learning processes are complex. There are no special "formulas", "ready recipes" to do "magical" motivational teaching practices, especially in cooperative work, at school (at family, with friends, in the social network) or at work, which is also a lifespan educational process, and must be positive, to a better quality in our life. Teaching and learning are cooperative processes, give many opportunities to participate actively in pedagogical practices (or at work), and propose more participation and inclusion of all participants, with simple changes and explicit known procedural rules and structures.

\section{References}

Antunes, D. D. (2016). Oficinas Pedagógicas Cooperativas: A motivação docente na formação continuada [Pedagogical Workshops Cooperatives: The Teaching Motivation in Continuing Education]. Curitiba: CRV.

Argimon, I. I. de L., Esteves, C. S., Cerutti, F., Mosquera, J. J. M., \& Stobäus, C. D. (2015). How to Get Better Aging, Bet on Positive Psychology. Psychology, 6, 1855-1860. http://dx.doi.org/10.4236/psych.2015.614182

Bardin, L. (2013). Análise de conteúdo [Content Analysis] (p. 70). 3. ed, Lisboa: Edições.

Coll, C., Marchesi, A., \& Palácios, J. (Org.) (2004). Desenvolvimento psicológico e educação. [Psychological development and education](2nd ed). Porto Alegre: Artmed.

de Jesus, S. N. (2004). Psicologia da educação [Educational Psychology]. Coimbra: Quarteto Editora.

de Jesus, S. N. (2007). Professor sem stress: realização e bem-estar docente [Teacher without Stress: Achievement and Teacher Welfare]. Porto Alegre: Mediação.

Deci, E. L., \& Ryan, R. M. (1985). Intrinsic Motivation and self determination in Human Behavior. New York: Plenum Publishing Co. http://dx.doi.org/10.1007/978-1-4899-2271-7

Deci, E. L., \& Ryan, R. M. (2000). The "What" and "Why" of Goal Pursuits: Human Needs and the Self-Determination of Behavior. Psychological Inquiry, 11, 227-268. http://dx.doi.org/10.1007/978-1-4899-2271-7

Dos Santos, B. S., Stobäus, C. D., \& Mosquera, J. J. M. (2007). Reflexões sobre o uso das Tecnologias de Informação e Comunicação no Ensino Superior [Reflections on the Use of Information and Communication Technologies in Higher Education]. In Memorias del 20. Simposium Iberoamericano en Comunicación del Conocimiento y Conferen-cias-CIAWI 2007 (pp. 247-252). Orlando: EEUU.

Dos Santos, B. S., Stobäus, C. D., Antunes, D. D., Bernardi, J., \& Villas-Boas, M. (2008a). As oficinas de auto-conhecimento e a motivação docente [The Workshops of Self-Knowledge and Teaching Motivation]. In XIV-ENDIPE-Encontro Nacional de Didática e Prática de Ensino 
Anais (pp. 1-8). Porto Alegre: EdiPUCRS.

Dos Santos, B. S., Stobäus, C. D., Mosquera, J. J. M., Antunes, D. D., \& Bernardi, J. (2008b). A motivação na formação docente continuada [The Motivation in Continuing Teacher Education]. In VII Seminário de Pesquisa em Educação da Região Sul-ANPEDSUL, Anais (pp. $1-12)$.

Esteve, J. M. (2004). A Terceira Revolução Educacional: A educação na sociedade do conhecimento [The Third Educational Revolution: Education in the Knowledge Society]. São Paulo: Moderna.

Huertas, J. A. (2001). Motivación: Querer Aprender [Motivation: Want to Learn]. Buenos Aires: Aiqué.

Mosquera, J. J. M. (1984). Psicodinâmica do aprender [Psychodynamics of Learning]. (3rd ed.) Porto Alegre: Sulina.

Mosquera, J. J. M., \& Stobäus, C. D. (1984). Educação para a Saúde [Heath Education]. (2nd ed.) Porto Alegre: D. C. Luzzatto.

Mosquera, J. J. M., \& Stobäus, C. D. (2016). Healthy Aging: Education, Health, Health Psychology, and Leisure. Creative Education, 7, 1261-1269. http://dx.doi.org/10.4236/ce.2016.79133

Mosquera, J. J. M., Stobäus, C. D., \& Dos Santos, B. S. (2013). Expanding Borders: Teachers Motivation. In C. Pracana, \& L. Silva (Eds.), Proceedings-Impact-International Psychological Applications Conference and Trends (pp. 1-5). Lisbon: W.I.A.R.S.

http://inpact-psychologyconference.org/wp-content/uploads/2014/04/InPACT_2013_Proceedi ngs.pdf

Piaget, J. (1987). O nascimento da inteligência na criança [The Birth of Intelligence in Children]. Rio de Janeiro: Guanabara.

Rodrigues, A. B. G. C., Stobäus, C. D., \& Mosquera, J. J. M. (2016). Identity as Study Object of Positive Psychology. Creative Education, 7, 1119-1125. http://dx.doi.org/10.4236/ce.2016.78116

Stake, R. E. (1998). Investigación con estudio de casos [Case Study]. Madrid: Ediciones Morata.

Stobäus, C. D., \& Mosquera, J. J. M. (2014). Positive Psychology and Emotional Schedule: Building Healthy Self-Construction. Psychology, 5, 533-540.

http://dx.doi.org/10.4236/psych.2014.56063

Vygotsky, L. S. (1989). A formação social da mente [The Social Formation of Mind]. São Paulo: Martins Fontes.

Submit or recommend next manuscript to SCIRP and we will provide best service for you:

Accepting pre-submission inquiries through Email, Facebook, LinkedIn, Twitter, etc.

A wide selection of journals (inclusive of 9 subjects, more than 200 journals)

Providing 24-hour high-quality service

User-friendly online submission system

Fair and swift peer-review system

Efficient typesetting and proofreading procedure

Display of the result of downloads and visits, as well as the number of cited articles

Maximum dissemination of your research work

Submit your manuscript at: http://papersubmission.scirp.org/ 